Instructions for authors, subscriptions and further details:

http://ijelm.hipatiapress.com

\title{
Educational leadership in Mexico
}

Isabel Parés ${ }^{1}$

1) Universidad Panamericana. México

Date of publication: July $16^{\text {th }}, 2015$

Edition period: July 2015-January 2016

To cite this article: Parés, I. (2015). Educational leadership in Mexico.

International Journal of Educational Leadership and Management, 3(2), 143172. doi: 10.17583/ijelm.2015.1575

To link this article: $\underline{\text { http://dx.doi.org/10.17583/ijelm.2015.1575 }}$

\section{PLEASE SCROLL DOWN FOR ARTICLE}

The terms and conditions of use are related to the Open Journal System and to Creative Commons Attribution License (CC-BY). 


\title{
Educational Leadership in Mexico
}

\author{
Isabel Parés \\ Universidad Panamericana
}

\section{Abstract}

Educational leadership in Mexico is an issue that was forgotten for decades, both in its formal structure and professional development. It finally started to become relevant in the context of the latest educational reform enacted in February 2013 and it has been implemented gradually under an adverse atmosphere between its supporters and some opponents that have pushed through peaceful and non-peaceful social actions, for the government to soften and/or eradicate some of the measures of the Education Reform. Specifically, the director's function from the perspective view of the Ministry of Education, is linked to the concept of school management, it is seen as a "modern" supervisor and manager of education. However, Mexico is in a process of professionalization of the management function, in order that school directors and supervisors become agents of change and improvement of educational quality in the country.

Keywords: dean, school director, director's functions and activities, director's profile, educational leadership, leadership and management competences in education, educational management in Mexico 


\section{Liderazgo Educativo en México}

Isabel Parés

Universidad Panamericana

\section{Resumen}

El liderazgo educativo en México es una tema que estuvo olvidado, en cuanto a su estructura formal y desarrollo profesional, por muchas décadas y que finalmente, empieza a cobrar relevancia dentro del contexto de la última Reforma Educativa promulgada en febrero 2013 y que poco a poco, se ha ido implementando, bajo un clima contradictorio entre quienes la apoyan y algunos opositores que han presionado con acciones sociales pacíficas y no pacíficas, para que el gobierno suavice y/o erradique algunas de las medidas de la Reforma Educativa. En concreto, la función directiva vista desde la perspectiva de la Secretaría de Educación Pública, está vinculada al concepto de Gestión Escolar, pues es visto como un supervisor y administrador "moderno" de la educación. Sin embargo, México se encuentra en un proceso de profesionalización de la función directiva, con la finalidad de que directivos y supervisores escolares, sean agentes del cambio y la mejora de la calidad educativa del país.

Palabras clave: director, dirección de instituciones educativas, liderazgo educativo, función directiva, perfil directivo, competencias directivas en el sector educativo, gestión educativa en México 


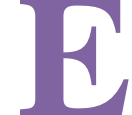

1 objetivo de este artículo es presentar una perspectiva general sobre el estado actual de la dirección de instituciones educativas en México, enfocándonos al rol del director escolar, de acuerdo a los estándares de la Secretaría de Educación Pública.

En primer lugar, revisaremos el contexto general del Sistema Educativo Mexicano (SEM), para delimitar el papel que desempeñan los directivos, desde su formación inicial, desempeño cotidiano y evaluación-, tanto en el contexto de la educación pública como de la privada y, transversalmente, se irán analizando los distintos niveles educativos: educación preescolar, básica, media superior y superior; aunque podemos adelantar que ahondaremos más en el directivo de educación básica, por ser la función en la que más ha trabajado la SEP.

La enseñanza primaria se consolida como el nivel educativo básico y elemental para el conjunto de la población ya desde las primeras décadas del siglo, conociendo una importante renovación metodológica y de contenidos en la segunda mitad del mismo. La enseñanza secundaria se ve sometida a una transformación profunda, pasando de constituir una etapa de contenido humanístico, minoritaria en número de alumnos y encaminada generalmente a la realización de estudios superiores, a convertirse en una etapa generalizada para el conjunto de la población, al menos en sus niveles iniciales, con opciones diversas y en la que se refuerza la presencia de contenidos de carácter científico y aplicado. Este cambio supone una reformulación de la enseñanza secundaria, de sus funciones y objetivos, en la totalidad de los países (Carreño, Colmenar, Egido y Sanz, 2002: 249).

En el caso específico de México, podemos decir que el quehacer educativo del futuro lo condiciona no sólo su presente sino también su pasado (Prawda, 1987), y por ello la importancia de estudiar los antecedentes que nos permitan entender el estado actual de la educación en el ámbito nacional.

Como elemento fundamental de nuestra aproximación al tema, consideramos que la escuela no es sólo una organización o empresa de servicios sino que es una institución en sí misma. 
Así la escuela debe ser instituida. Claro está que tenemos el derecho -el deber incluso- de querer mejorar el funcionamiento del servicio público de la educación en todos los campos, desde la calidad de los edificios hasta la organización del empleo del tiempo, desde la utilización de las tecnologías de la comunicación hasta la gestión del personal. Debemos trabajar para que las condiciones de escolarización sean lo más equitativas posible, que todos los niños puedan beneficiarse realmente de buenas escuelas y buenos docentes [...] pero todo esto siempre debe hacer referencia a los principios fundadores de la institución Escuela. Para hacer progresar a la escuela, hay que saber cómo hacer Escuela (Meirieu, 2004: 22).

La institución educativa, liderada por el director escolar, es la responsable de formar a los ciudadanos que forjarán el futuro de México, pero esto no se logrará sin un gran esfuerzo por parte de las políticas educativas y su implementación, en todos los ámbitos e integrantes que conforman el Sistema Educativo Mexicano. Es momento de que México implemente la Reforma Educativa 2013, para dejar atrás el modelo de Escalafón creado en 1973, que permitía acceder a diversos puestos, como el directivo.

\section{Desarrollo}

Comenzaremos por explicar de manera general el panorama educativo en México y los cambios que se han presentado recientemente, derivados de la Reforma Educativa 2013.

\section{Sistema educativo mexicano}

El Sistema Educativo Mexicano es el conjunto de normas, instituciones, recursos y tecnologías destinadas a ofrecer servicios educativos y culturales a la población, de acuerdo con los principios ideológicos que sustentan al Estado mexicano. Están expresados en el artículo tercero constitucional, el cual es producto de la confluencia de dos corrientes de pensamiento: el liberalismo mexicano que se reafirmó con la Guerra y las Leyes de Reforma de 1859 y 1861, respectivamente y los principios de justicia social, vida democrática, no reelección y participación estatal en el quehacer educativo 
nacional que postuló la Revolución mexicana. Ambas se conjugan en la Constitución de 1917, que en la actualidad rige la vida en la nación

El SEM es un "cosmos institucional complejo, que se diferencia por modalidades y niveles, con propósitos a veces contradictorios y prácticas que niegan los fines explícitos de la educación; todo, producto de una historia de más de 70 años, cargada de tensiones, logros y fracasos" (Ornelas, 1995: 28).

La cualidad más importante del SEM, que lo distingue de otros países capitalistas (avanzados y en vía de desarrollo), es la función del Estado en su institución y funcionamiento. Todos los países tienen sistemas de educación pública; en todos, los gobiernos son los que canalizan los recursos fiscales, y en todos ellos, las políticas gubernamentales tienen secuelas en el quehacer del sistema. Pero en el caso del SEM, su dependencia del Estado es casi absoluta, no sólo como resultado de una política de un gobierno determinado, sino que, a partir de 1917, dada una confluencia amplia de intereses y después de la guerra revolucionaria, se estableció el principio del Estado educador en la Constitución y la realidad mexicanas.

El 5 de septiembre de 1921 se creó la Secretaría de Educación Pública como el organismo rector de la educación nacional que debería hacer sentir su acción civilizadora donde fuera necesario. La SEP, de acuerdo con su impulsor, José Vasconcelos, debería ser una institución flexible, ilustrada y poderosa, que diera sentido a la idea de mexicanidad y se encargara de educar al pueblo (Ornelas, 1995: 285).

Como cualquier otra dependencia gubernamental, la Secretaría de Educación Pública (SEP) un aparato burocrático cuyo titular es el Secretario de Educación Pública -actualmente el licenciado Emilio Chuayffet Chemor, quien delega funciones en Subsecretarías de Educación Básica, Media Superior y Superior, así como una Oficialía Mayor.

\section{Estructura del SEM}

La educación básica consta de tres niveles. El primero es el preescolar, que tiene por objeto estimular a los niños de entre tres y cinco años de edad para la formación de hábitos y la ampliación de aptitudes escolares. Se cursa en tres grados y equivalen a los primeros tres años de escolaridad en México. 
Cabe aclarar que a partir de la reforma al artículo tercero constitucional, en noviembre de 2002, el nivel preescolar forma parte de la educación básica obligatoria, incorporación que se ha realizado de manera gradual entre los ciclos 2004/2005 y 2008/2009 y que continúa en la actualidad.

Este ciclo educativo precede a la enseñanza primaria. Durante el primero y segundo grados de preescolar se atienden a los niños de tres y cuatro años; en el tercero, a los de cinco. No obstante, para cursar el segundo o tercer grados no es condición haber cursado el grado o grados anteriores. La educación preescolar se ofrece en tres modalidades: general, indígena y cursos comunitarios.

El objetivo general de la educación preescolar es promover el desarrollo físico, intelectual, afectivo, moral, artístico, social y familiar del niño, lo cual implica que el alumno desarrolle:

a) Autonomía e identidad personal.

b) Formas sensibles de relación con la naturaleza, que lo preparen para el cuidado de la vida en sus diversas manifestaciones.

c) Socialización a través del trabajo grupal y la cooperación con otros niños y adultos.

d) Formas de expresión creativas por medio del lenguaje, de su pensamiento y de su cuerpo.

El segundo nivel es la educación primaria, cuyo objetivo general es propiciar el desarrollo de las habilidades básicas matemáticas y lingüísticas (lectura y escritura), así como iniciar a los niños en el conocimiento de las ciencias y las disciplinas artísticas. La Constitución Política de México establece el carácter obligatorio de la educación primaria, la cual se imparte en seis grados a los niños en edad escolar, es decir, que tienen de seis a catorce años, en los medios urbano y rural. Incluye ocho asignaturas: español, matemáticas, ciencias naturales, historia, geografía, educación cívica, artística y física. Asimismo, en este nivel se ofrece educación para los adultos.

La misión principal de la escuela primaria mexicana es formar ciudadanos solidarios y preparados para la vida democrática, sin embargo, a veces parece reproducir en su quehacer rasgos autoritarios perceptibles. Se producen millones de libros de texto, no obstante, hay opiniones de peso que denotan que los contenidos educativos son obsoletos e irrelevantes para la sociedad actual y futura. Se postula que la educación es el mejor instrumento para preparar recursos humanos que demanda el desarrollo del país, pero el 
sistema educativo no considera en valores que enaltezcan el trabajo. Se ha logrado una cobertura notable en la educación básica, sin embargo, la calidad de la misma es aún deficiente, en especial en las zonas rurales y pobres de las ciudades, que se acentúa en los grados superiores. En suma, la educación siempre ha sido la esperanza de un futuro mejor, pero su presente deja mucho que desear (Ornelas, 1995).

En cualquiera de sus modalidades, la educación primaria es propedéutica (es decir, previa e indispensable) para la educación secundaria. El alumno que la concluye con éxito recibe un certificado que acredita su preparación.

En el caso de la educación secundaria su objetivo general es proporcionar a los estudiantes conocimientos más avanzados que les permitan continuar con sus estudios en el nivel medio superior o incorporarse al sector productivo. Se cursa en tres grados por jóvenes generalmente de entre 12 y 14 años de edad. (Instituto Nacional para la Evaluación de la Educación, 2007). En este nivel se busca fomentar el desenvolvimiento de la personalidad del educando, iniciado durante la primaria; estimular sus aptitudes para que participe en su propia formación; proporcionar los conocimientos necesarios para ingresar a ciclos posteriores, así como el adiestramiento en actividades industriales, comerciales, agropecuarias o pesqueras.

El siguiente nivel educativo es el medio superior. Éste tiene una doble finalidad: dar al estudiante elementos para elegir entre las opciones de educación superior al cursar el bachillerato, o bien capacitarlo en actividades diversas enfocadas al ámbito laboral, si lo cursa como profesional técnico. La educación media superior sólo es de un nivel y su duración generalmente es de tres años, o menos, según el plan de estudios. A ella asisten principalmente jóvenes entre los 15 y 17 años de edad.

Dicho nivel comprende tres tipos de educación: propedéutica, propedéutica-terminal y terminal. Los dos primeros se imparten en las modalidades escolarizada y abierta. La escolarizada atiende generalmente a la población de 16 a 19 años de edad que haya obtenido el certificado de secundaria. El propedéutico se conoce también como bachillerato general. La mayor parte de las escuelas sigue un plan de estudios de tres años de duración, sin embargo, en otras se cursa en dos. Al concluir su aprendizaje, los alumnos pueden acceder al nivel superior. El bachillerato general pretende ampliar y consolidar los conocimientos adquiridos en secundaria y 
preparar al educando en todas las áreas del saber para que elija y curse estudios superiores.

El último nivel de esta estructura es la educación superior, que ofrece la profesional y la especialización. La primera corresponde a licenciatura y técnica superior, con el propósito de preparar estudiantes en alguna disciplina o conocimiento específicos para el ejercicio autorizado y profesional de una actividad. La segunda equivale a posgrados que brindan materias más acotadas. Los estudios profesionales tienen una duración de entre tres y seis años de acuerdo con el plan académico. En su mayoría ingresan estudiantes de 18 años de edad. Los programas de posgrado se llevan a cabo, según el nivel de especialización, en un lapso de entre uno y cuatro años.

A continuación se muestra un esquema con información general del Sistema Educativo Mexicano.

Tabla 1.

Niveles y modalidades del Sistema Educativo Mexicano ${ }^{1}$

\begin{tabular}{|c|c|c|c|c|c|c|}
\hline Nivel & Inicial & Preescolar & Primaria & Secundaria & Bachillerato & Superior \\
\hline Edad & $\begin{array}{c}\text { De 45 } \\
\text { días a 5 } \\
\text { años 11 } \\
\text { meses }\end{array}$ & $4-5$ años & $6-14$ años & $12-16$ años & $16-19$ años & $\begin{array}{c}20 \text { años } \\
\text { en } \\
\text { adelante }\end{array}$ \\
\hline $\begin{array}{c}\text { Duración } \\
\text { (grados y } \\
\text { años) }\end{array}$ & $\begin{array}{c}3 \text { grados } \\
1 \text { a } 3 \text { años }\end{array}$ & $\begin{array}{c}6 \text { grados } \\
6 \text { años }\end{array}$ & $\begin{array}{c}3 \text { grados } \\
3 \text { años }\end{array}$ & $\begin{array}{c}2 \text { a } 3 \text { grados } \\
2 \text { a } 3 \text { años }\end{array}$ & Variable \\
\hline
\end{tabular}

Podemos mencionar que respecto de la infraestructura educativa, debido a los esfuerzos pioneros y visionarios de Jaime Torres Bodet, quien fue secretario de Educación, de 1945 a 1946 y de 1958 a 1964, "el Estado mexicano provee de espacios educativos a la población que acude a los establecimientos públicos" (Prawda y Flores, 2001: 119).

El gran conjunto articulado que forman los niveles y servicios descritos hasta aquí recibe el nombre de Sistema Educativo Escolarizado. El nombre tiene una finalidad práctica, que es la de diferenciarlo de aquellos 
servicios ofrecidos por el SEM a la población que, por múltiples razones, no es atendida por el sistema escolarizado. Paralelamente, el SEM integra otros servicios diseñados para atender necesidades educativas diferentes a las que contempla la estructura anterior y lo hace a través de las modalidades abierta no escolarizada o semiescolarizada, por lo cual se les denomina, en conjunto, Sistema Educativo Extraescolar (Instituto Nacional para la Evaluación de la Educación, 2007: 33-34).

Recordemos que el artículo tercero de la Constitución Política de los Estados Unidos Mexicanos y la Ley General de Educación (LGE) son los principales documentos legales que regulan al sistema educativo nacional. Éstos, definen los principales objetivos, intenciones y fundamentos educativos y establecen las disposiciones de carácter normativo, técnico, pedagógico, administrativo, financiero y de participación social (Prawda y Flores, 2001).

El artículo tercero constitucional compromete a que toda persona tiene derecho a recibir educación y que la federación, los estados y los municipios la ofrecerán en los niveles preescolar, primaria y secundaria. La educación impartida por el Estado tenderá a desarrollar armónicamente las facultades del ser humano y fomentará el amor a la patria y la conciencia de la solidaridad internacional, en la independencia y en la justicia. El artículo estipula ofrecida por toda la educación que el Estado será gratuita; suscitará y atenderá todas las modalidades educativas, incluyendo la superior; apoyará la investigación científica y tecnológica, y alentará el fortalecimiento y difusión de la cultura de México.

El Ejecutivo Federal determina los planes y programas de estudio de la educación primaria, secundaria y normal para toda la República, tomando en cuenta las opiniones de los gobiernos de las entidades federativas y de los diversos sectores involucrados. La educación impartida por el Estado es laica, por tanto ajena a cualquier doctrina religiosa; está orientada por los resultados del progreso científico y lucha contra la ignorancia, las servidumbres, los fanatismos y los prejuicios. En la actualidad, la educación en México se apega al Programa Nacional de Desarrollo 2014-2018, que fue elaborado a partir de las Reformas Estructurales recién promulgadas por el Ejecutivo Federal, es decir, el Presidente de la República.

La educación también se encauza por el criterio democrático, al considerar a la democracia no sólo como estructura jurídica y régimen 
político, sino como un sistema de vida fundamentado en el constante mejoramiento económico, social y cultural del pueblo; por el criterio nacional para comprender, sin hostilidades ni exclusivismos, los problemas del país: aprovechamiento de los recursos, defensa de la soberanía política, aseguramiento de la independencia económica y continuidad y acrecentamiento de la cultura mexicana. La educación debe contribuir a la mejora de la convivencia humana, al aprecio por la dignidad ${ }^{2}$ e integridad de la persona y la familia, al interés general de la sociedad, al cuidado para sustentar los ideales de fraternidad e igualdad de derechos de todos los hombres, evitando los privilegios de razas, religión, grupos, sexos o individuos.

El artículo tercero constitucional da facultad a los particulares de impartir educación en todos los tipos y modalidades. El Estado otorga y retira el reconocimiento de validez oficial de los estudios realizados en los planteles particulares. La educación primaria, secundaria y normal que impartan los particulares apegarse a seguir los criterios generales establecidos en este artículo, pero no está obligada a ser laica. Por su parte, las universidades y demás instituciones de educación superior a las que la ley otorga autonomía, tendrán la facultad y responsabilidad de gobernarse a sí mismas; realizarán sus fines de educar, investigar y difundir la cultura de acuerdo con los principios de este artículo, respetando la libertad de cátedra e investigación y de libre examen y discusión de las ideas; determinarán sus planes y programas; fijarán los términos de ingreso, promoción y permanencia de su personal académico y administrarán su patrimonio ${ }^{3}$.

\section{Situación actual del SEM}

El sistema educativo tiene la obligación de formar los recursos humanos que demanda el país, instruir productores eficientes para modernizar México educar a los hombres y mujeres del siglo XXI, quienes enfrentarán severas metamorfosis en la organización social y en la división del trabajo. México, necesita una educación eficiente para estar a la altura de los cambios que se avecinan, por ello la urgencia que hubo en la última década para promulgar la Reforma Educativa 2013; sin embargo, cabe aclarar que la implementación se ha tenido que atenuar, pues las fuerzas políticas del Sindicato Nacional de Trabajadores de la Educación (SNTE) y su disidencia, la Coordinadora Nacional de Trabajadores de la Educación (CNTE) han 
presionado de distintas maneras para frenar cambios profundos que pueden coadyuvar a la mejora de la educación.

A pesar de la existencia de grupos aferrados al modelo de crecimiento profesional Escalafón, creado en 1973, es claro que México necesita transparentar los procesos de selección y nombramiento de directores; además de su formación inicial y permanente (López Delgado, 2015). Es así como la calidad educativa influye directamente en una sociedad del conocimiento que se encuentra sumergida en una inercia de movilidad social.

La educación es uno de los muchos factores que contribuyen a la movilidad social y quizá no sea el más importante, pero ideológicamente se presenta como el preponderante. En México, al igual que en casi todo el mundo, la educación es un derecho, pero contrariamente a otros derechos como la libertad de tránsito o de prensa, donde el Estado constitucionalmente sólo debe ser el garante de que se cumplan, en el caso de la educación, tiene la obligación de ofrecer de manera gratuita a la primaria y la secundaria a todos quienes estén en edad de recibirla (Ornelas, 1995: 208).

El SEM debe continuar su proceso de modernización y mantenerlo hasta alcanzar, por lo menos, dos propósitos fundamentales:

a) Asegurar a un mayor número de mexicanos educación básica, cualquiera que ésta sea, de mejor calidad que la actual.

b) Preparar la transición gradual y ordenada hacia un proyecto educativo que se asemeje más al tipo cultural y evitar, a toda costa, caer inesperadamente en un modelo regresivo de congelamiento político, mismo que inevitablemente habremos de presenciar de no realizarse algunos o la totalidad de los cambios estructurales requeridos.

Algunos de los pilares de la actual Reforma están basados en: el inicio de la descentralización educativa ${ }^{4}$; la jerarquización explícita de prioridades y metas del quehacer educativo; el Programa de promoción en la función por incentivos de la Educación Básica, que viene a sustituir; los lineamientos del servicio profesional docente, dentro de los cuales se empiezan a sembrar las bases para la formación de directivos escolares.

Previo a esta Reforma, podemos ver que la transformación de la educación básica y normal en México ha requerido una paulatina y profunda 
reorganización del sistema educativo, basada en el federalismo y en nuevas relaciones entre el Estado y la sociedad. En el marco del Acuerdo Nacional para la Modernización de la Educación Básica (ANMEB), firmado por el gobierno federal, los gobiernos estatales y el Sindicato Nacional de Trabajadores de la Educación en mayo de 1992, y de los convenios entre el gobierno federal y los gobiernos de los estados de la República, se inició un proceso de federalización educativa.

Los servicios de educación preescolar, primaria y secundaria, de formación de maestros y de educación indígena y especial que operaba el Poder Ejecutivo Federal, fueron transferidos a los estados. Así, los inmuebles escolares $y$ de oficinas, mobiliario, personal docente, administrativo y de servicios, y los recursos financieros pasaron al control de los gobiernos estatales, incluyendo las unidades estatales de la Universidad Pedagógica Nacional. El gobierno federal sólo conservó la dirección y operación de los planteles de educación básica y de formación de maestros en el Distrito Federal, y se comprometió a transferir recursos suficientes para que cada gobierno estatal tenga la posibilidad de elevar la calidad y cobertura de los servicios de educación a su encargo ${ }^{5}$. Los gobiernos estatales, a su vez, se comprometieron, junto con el gobierno federal, a otorgar recursos a la educación considerablemente superiores a las del crecimiento del Producto Interno Bruto (PIB).

Podemos decir que nuestro país tiene en detrimento que el SEM nunca se encaminó a la formación de investigadores, a la implantación de modelos que pusieran acento en el descubrimiento y la creación. Y ése es un defecto que abarca desde la primaria hasta muchos posgrados que no son más que programas remediales a la baja calidad de la educación profesional (Ornelas, 1995: 183).

La implementación de la Reforma Educativa representa un nuevo reto para modernizar la educación en México es racionalizar metódicamente los costos educativos y, a la vez, ordenar y simplificar los mecanismos para su manejo y administración e innovar en los procedimientos. Además, se ha propuesto revisar los contenidos, renovar los métodos, privilegiar la formación de maestros, articular los distintos niveles educativos y vincular los procesos pedagógicos con los avances de la ciencia y de la técnica. El desafío en su conjunto consiste en reducir el rezago educativo en materia de 
primaria, constitucionalmente obligatoria. Lo anterior sólo podría lograrse si se realiza un cambio estructural del sistema educativo, cuya base sea una política de descentralización que permita distribuir en forma efectiva la función educativa, con objeto de que cada nivel de gobierno y todos los sectores de la sociedad contribuyan en esta tarea.

La labor de evaluar la política pedagógica a través del consumo y el resultado en la educación es complicado porque no existen datos suficientes que nos permitan medir cambios en ni tampoco hay un plan educativo de diez años que nos dé la oportunidad de evaluar conforme a lo que el mismo plan hubiese establecido en 1990. Lo más cercano en este sentido es el Acuerdo para la Modernización de la Educación Básica (ANMEB), en el que se establecen tres líneas fundamentales de estrategia para impartir una educación con cobertura suficiente y con calidad adecuada (Andere, 2003): reorganización del sistema educativo, reformulación de contenidos y materiales didácticos y revaloración social de la función magisterial.

La idea de gastar más en educación en principio no es una mala idea, suena bien. Sin embargo, cuando la concreción de la idea implica determinar la cantidad óptima a gastar, la idea se convierte en un formidable problema. Para los políticos es muy fácil presionar y exigir, más gasto para la educación, es una idea que se vende bien. Sin embargo puede ser usada con irresponsabilidad y demagógicamente. Con base en esa idea, el Congreso de la Unión aprobó, y el presidente promulgó en diciembre de 2002, reformas a la Ley general de educación que exigen al Estado -federación, entidades federativas y municipios- destine el gasto en educación pública y en los servicios educativos un monto no inferior al 8\% del PIB (Andere, 2003: 25).

El mismo Andere nos comenta que presupuesto o gasto no lo es todo. Digamos que es condición necesaria, pero no suficiente. Se necesita comprobar que el presupuesto ejercido tiene efectos positivos sobre un área de acción de políticas públicas como es la educación. Sin embargo, a diez años del inicio de este amplio y complejo proceso de reforma de la educación y del SEM se puede afirmar que sus efectos han sido positivos. Esto se observa principalmente en el incremento de la matrícula, en el mejoramiento de los indicadores de eficiencia terminal y en los índices de absorción de un nivel educativo a otro. No obstante, desde una perspectiva 
estructural, los cambios más profundos que necesita el SEM y la transformación de los directivos y líderes que tienen en sus manos las instituciones educativas.

Por ejemplo, durante décadas, políticos y académicos postularon que el principio de justicia social en la educación era proveer igualdad de oportunidades en el acceso a la escolaridad. Sin embargo, detrás del concepto de igualdad de oportunidades (educación para todos, ampliación de la oferta, etcétera) se oculta el principio de inequidad ya que, en el mejor de los casos, se ofrecen las mismas oportunidades a los ricos y a los pobres, a los habitantes de las ciudades y a los de las zonas rurales, sin tomar en cuenta que por el origen social tienen necesidades diferentes y demandan un trato diferenciado (Ornelas, 1995: 45).

Sin embargo, la equidad también requiere de efectividad, entendida como la forma de medición que nos indica el grado de adquisición, en el educando, de las competencias señaladas en los planes y programas de estudio: "puede haber sistemas educativos efectivos (cumplen con su objetivos) pero no pertinentes (están desconectados de su contexto) y al revés: los hay también inefectivos y no pertinentes, y efectivos pertinentes" (Prawda y Flores, 2001: 139).

\section{El director escolar en la educación pública en México}

Al comienzo del ciclo escolar 2014/20015, según fuentes electrónicas de la Secretaría de Educación Pública, el SEM en su modalidad de Educación Básica, incluyó cerca de 25 millones 900 mil alumnos en el conjunto de los servicios que ofrece. De ellos, el $90.38 \%$ asisten a las instituciones públicas, encabezadas por un director escolar, que reporta a un supervisor de zona escolar. Resulta más importante aún la participación porcentual del sector público en la secundaria: aproximadamente sólo $7 \%$ de su matrícula es atendida en escuelas privadas.

Los alumnos en la escuela primaria generalmente tienen un maestro a lo largo del año escolar, a veces por menos tiempo debido a la elevada rotación del personal en algunas áreas; en raras ocasiones el mismo maestro comparte a un grupo en dos años diferentes. Las características principales de los niños, más allá de sus disparidades en cuanto a su capacidad intelectual, 
dedicación y motivación personal para el estudio, son más o menos homogéneas. Hay muchas variaciones entre una escuela y otra, pero en un salón de clases dado la uniformidad es la regla: casi todos los niños viven en el mismo vecindario, que tiene también peculiaridades del segmento social al que pertenecen; no hay muchas variaciones en sus edades y, se puede pensar, tienen gustos similares, ven los mismos programas en televisión y comparten aficiones semejantes por algún deporte. En las aulas de la escuela primaria sólo hay un maestro o maestra, quienes son el centro del proceso escolar.

Del total de personal dedicado a la educación básica en México, el 5\% corresponde a directivos que exclusivamente dedican su tiempo a temas de gestión y administración escolar; sin embargo, existe un 4\% de personal contratado por la SEP, que desempeña el puesto de director, pero que a su vez realiza también actividades docentes en el aula.

Esto nos lleva a la conclusión de que el 9\% del personal que trabaja en la Educación Básica, tiene el puesto de Director Escolar, pero dentro de este porcentaje, el $55 \%$ se dedica exclusivamente a las labores directivas y alarma, conocer que un $45 \%$ de los Directores tienen que desempeñar una doble función como líder de la institución educativa y realizando actividades frente a grupo. Lo preocupante de esta situación, es que si los directores no tienen clara sus funciones y el tiempo de dedicación, difícilmente las escuelas podrán alcanzar sus metas en cuanto a calidad educativa se refieren. Estos datos se pueden cotejar y ampliar de manera electrónica en el Sistema de Información y Gestión Educativa (SIGED) dependiente de la SEP.

Si retomamos que el 9\% del personal de Educación Básica de la SEP desempeña puestos directivos, es contrastante ver que el $24 \%$ está conformado por jefes de enseñanza, supervisores, prefectos, administrativos y personal e servicios.

A continuación presentamos una gráfica que nos simplifica entender este contexto. 


\section{Total de personal dedicado a la Educación Básica en la SEP}

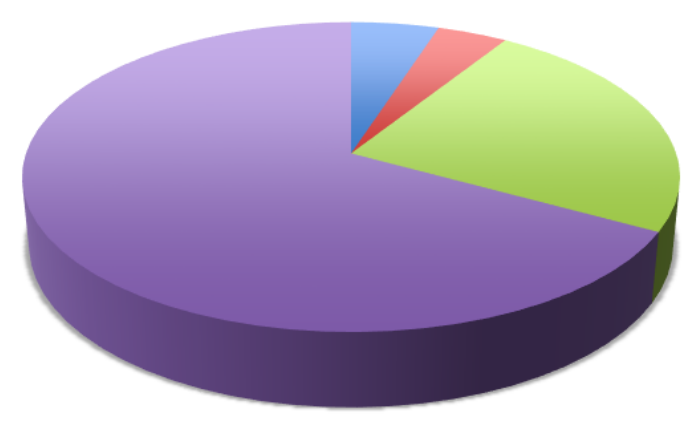

- Directores

Directores frente a grupo

- Jefesde enseñanza, supervisores, perfcetos, administrativos y personal de servicios

Docentes

Figura 1. Total de personal dedicado a la Educación Básica en la SEP.

En esta gráfica, se demuestra que es bajo el índice de directivos escolares que se dedican a la Dirección como labor exclusiva; y a partir de ahí surge la pregunta si todos ellos, el 5\%, tienen el perfil mínimo requerido, que se publicó para el ciclo 2015-2016 o si muchos de ellos han desempeñado el puesto a lo largo del tiempo sin perfil y/o capacitación pertinentes. Sin embargo, esta interrogante no la podremos aclarar dada la falta de información proporcionada por la misma Secretaría d Educación Pública y a que en la década pasada no se contaba con un perfil claro y definido de la figura del director escolar.

En palabras de la SEP, el perfil para directivos de educación básica en la actualidad, expresa las características, cualidades y aptitudes deseables para el desempeño eficiente de las funciones del personal directivo en las escuelas de educación básica. Asimismo, es un referente para la formación continua y facilitador de políticas y programas que ayuden en el fortalecimiento de la labor docente. El perfil del director escolar lo delinea como pieza clave para planear, coordinar y sostener en conjunto con el 
equipo docente la mejora del proceso enseñanza - aprendizaje, así como incrementar el índice de autonomía en la gestión (SEP, 2015: 13).

El nombramiento de directores en las escuelas de educación básica en México, enfrenta la necesidad de actualizar el "sistema de promoción debido a que los directores escolares son promovidos al cargo mediante procedimientos y reglamentos que fueron promulgados hace más de 40 años. El sistema actual no favorece el nombramiento de directores escolares preparados para el puesto" (López Delgado, 2015: 56). Nos deja el panorama claro sobre la necesidad inminente de preparar para el puesto a quienes aspiran a él y, por otro lado, dar capacitación permanente a quienes ya ocupan puestos directivos.

Para este próximo ciclo escolar, la SEP plantea que el director debe cubrir un perfil que incluye diversas dimensiones, de las que derivan parámetros e indicadores; todo ello encaminado a la misma finalidad: que los alumnos de la escuela aprendan con calidad y equidad. A continuación presentamos las cinco dimensiones fundamentales que fungen como eje rector del perfil directivo de educación básica en México (SEP, 2015: 1634):

a) Dimensión 1: Un director que conoce a la escuela y el trabajo en el aula, así como las formas de organización y funcionamiento de la escuela para lograr que todos los alumnos aprendan.

a. Reconoce la tarea fundamental de la escuela.

b. Identifica los rasgos de la organización y el funcionamiento de una escuela eficaz.

c. Identifica los componentes del currículo y su relación con el aprendizaje de los alumnos.

d. Identifica los elementos del trabajo en el aula y las prácticas docentes.

b) Dimensión 2: Un director que ejerce una gestión escolar eficaz para la mejora del trabajo en el aula y los resultados educativos de la escuela.

a. Ejerce el liderazgo directivo para propiciar la autonomía de gestión de la escuela.

b. Determina acciones para promover la mejora escolar.

c. Identifica estrategias para promover el trabajo colaborativo en la escuela 
d. Determina estrategias para la gestión, administración u uso de los recursos, espacios físicos y materiales educativos.

c) Dimensión 3: Un director que se reconoce como profesional que mejora continuamente para asegurar un servicio educativo de calidad.

a. Explica la finalidad de la reflexión sistemática sobre la propia práctica profesional.

b. Considera el estudio y la participación en redes y comunidades de aprendizaje, como medios para su desarrollo profesional.

c. Explica la contribución de las Tecnologías de la Información y la Comunicación (TIC) en el fortalecimiento y desarrollo de la tarea directiva.

d) Dimensión 4: un director que asume y promueve los principios legales y éticos inherentes a su función y al trabajo educativo, a fin de asegurar el derecho de los alumnos a una educación de calidad.

a. Asumen los principios filosóficos, as disposiciones legales y las finalidades de la educación pública mexicana.

b. Gestiona ambientes favorables para el aprendizaje, la sana convivencia, la inclusión educativa y la seguridad en la escuela.

c. Distingue las actitudes y capacidades necesarias para ejercer la función directiva.

d. Reconoce el papel del director para asegurar el derecho de los alumnos a una educación de calidad.

e) Dimensión 5: Un director que conoce el contexto social y cultural de la escuela y establece relaciones de colaboración con la comunidad, la zona escolar y otras instancias, para enriquecer la tarea educativa.

a. Reconoce la diversidad cultural y lingüística de la comunidad y de los alumnos, y su vínculo con la práctica educativa.

b. Promueve la colaboración de las familias, la comunidad y otras instituciones en la tarea directiva de la escuela.

c. Propone estrategias de colaboración entre el director, la supervisión y otros directivos de la zona escolar.

Este perfil será, mediante el cual se evalúe por primera, conforme a lo que señala la Ley General de Servicio Profesional Docente, durante el año 2015, a quienes participen en los Concursos de Oposición para la Promoción a cargos con funciones de dirección y supervisión en educación básica, así como a funciones de asesoría técnica pedagógica. 
Conforme a dichas dimensiones, parámetros e indicadores, el Instituto Nacional para la Evaluación de la Educación (INEE) ha elaborado instrumentos de evaluación, previa validación y autorización, para promoción de docentes hacia otras funciones de la actividad escolar.

Este cambio, implica un avance inédito para el Sistema Educativo Mexicano, pues no existía un perfil directivo, ni instrumentos que validaran que los candidatos tuvieran el perfil necesario para cubrir actividades de índole directiva. El rezago educativo en México, es evidente y conocido a nivel mundial, pero no se puede atribuir a un solo factor determinante, sino a la suma de desorganización de la estructura escolar -evidenciada en que no existiera un documento formal y contundente en el que se delineara el perfil directivo ni mecanismos formales de ingreso a dichas posiciones-, la poca actualización de planes y programas de estudio, la baja calidad en la formación docente -profesional y continua-, y un amplio etcétera en el que influyen de manera preponderante la burocracia y guerras de control educativo y poder económico entre el Estado y los Sindicatos: el SNTE y la CNTE.

Si cambiamos un poco la mirada de la educación básica, hacia la educación media superior y superior la situación varía en algunos aspectos. Los jóvenes ya no tienen un solo maestro para todas las materias, sino diez o doce distintos; por tanto, el grupo docente que lidera el director escolar, es mayor en cantidad y con necesidades de formación profesional más específicas. Los jóvenes de una secundaria o preparatoria no necesariamente pertenecen al mismo segmento social y hay un mayor grado de diferenciación de intereses y vocaciones (Ornelas, 1995). Aquí existe un mayor reto a enfrentar, no sólo como directivo escolar, sino para el Estado mexicano: jóvenes que al egresar del bachillerato no encuentran un espacio en el sector productivo nacional, es decir, aquello que estudiaron no les permite acceder a una mejor calidad de vida y generar un ingreso. Por eso comenzó la reforma del nivel medio superior, sobre el entendido de que el compromiso por parte de la Secretaría de Educación Pública, y todo el sector productivo, debía establecer estrategias y llevar a cabo acciones para lograr que el sistema educativo ofreciera $-\mathrm{y}$ podemos decir que ofrezca, pues es una tarea a la cuál le falta un largo camino-, a sus egresados mayores niveles de competitividad.

Es preciso que el SEM garantice a los alumnos que cursan el bachillerato, en la actualidad más de tres millones, podrán transitar por un "muy buen 
puente" al mundo productivo. De igual forma, las empresas se deberán vincular con las escuelas en programas encaminados a conseguir ese objetivo. Se tiene que lograr que estos jóvenes sean capaces de generar un ingreso que les permita vivir con menos miedos, que les permita ser mucho más libres de lo que son, tengan oportunidad de iniciar un ciclo de ahorro; en suma, que contribuyan a crear las bases de la prosperidad del país ${ }^{6}$.

\section{Liderazgo en la educación pública-educación privada}

La educación pública actualmente es laica, gratuita y obligatoria; la educación privada se caracteriza por sostenerse con fondos no gubernamentales y por añadir materias, contenidos o, lo que hoy llamamos, un valor agregado a la enseñanza.

La escuela debe ser entendida como una institución especializada, paulatinamente normalizada y que cumpla con la función de instruir, formar e introyectar conocimientos y normas comunes, además de valores y tradiciones propias de un grupo social. Esta doble función de la educación la de ser una y múltiple, en palabras de Durkheim- constituye la dimensión en la que se insertan las tensiones entre el poder público y el poder privado, y entre lo que se considera el bien común y los intereses particulares desde la perspectiva del Estado.

El sector de escuelas particulares ${ }^{7}$ que se estructuró a lo largo del siglo $\mathrm{XX}^{8}$ en México, es diverso y complejo. Una parte sustancial aún son las instituciones de orientación católica, bien sean atendidas por profesores laicos o por congregaciones religiosas; pero junto con ellas están, por ejemplo, los colegios extranjeros y las escuelas que ostentan un modelo pedagógico innovador. Una característica de las escuelas particulares en este siglo es que se han expandido también a partir de atender los niveles educativos que el gobierno ha sido incapaz de cubrir cabalmente: educación inicial (sobre todo guarderías infantiles), preescolar, primaria, secundaria y, actualmente, educación media superior y superior.

Para nosotros es inevitable decir que las escuelas privadas orientan su oferta educativa a sectores sociales con los cuales se identifican cultural y socialmente. Los padres de familia que acuden a estas instituciones pagan por un servicio que esperan supere las expectativas puestas en las escuelas públicas y que le otorgue el valor agregado, antedicho, a la formación de sus hijos $^{9}$. Ante este reto, el director de la escuela privada debe satisfacer las 
expectativas de los padres de familia y, a su vez, cubrir las obligaciones que le exige el Estado.

En este mercado educativo de ofertas y demandas diversas, el libre juego de fuerzas, aunado al relajamiento sobre la vigilancia de las escuelas particulares, procura las condiciones necesarias para el fraude; cuando éste se da es doblemente reprobable, pues además de no cumplir con el servicio educativo por el que los padres de familia pagan, se trafica de manera mercantil con la formación de seres humanos ${ }^{10}$; y por ello, el valor tan alto que tiene la formación ética del director escolar, que no debe prestarse al juego de fuerzas, sino ver, por encima de todo, la calidad educativa de sus alumnos y la excelencia profesional del docente, pues sin este binomio, se puede perder la meta de su función directiva.

Uno de los aspectos menos conocido sobre la educación privada en México es su heterogeneidad. De hecho, en la mayoría de las discusiones políticas o académicas sobre ese sector se hace tabula rasa, se supone que es uniforme y que responde a los mismos intereses. Por ejemplo, muchas escuelas brindan educación bilingüe, pero en cada una se entiende de distinta manera: algunas ofrecen tan sólo una clase de inglés a la semana y otras sí imparten asignaturas del currículo en inglés. Otro ejemplo puede ser el de desarrollo psicomotor, que en algunas instituciones lo confunden con la mera educación física y no cuentan con programas e instituciones especializados.

La evidencia disponible muestra que no toda la educación privada es necesariamente buena o de mejor calidad que la enseñanza pública, ni que persiga fines antinacionales y conservadores, como acusan algunos de sus adversarios. Su crecimiento se debe, tal vez, a ciertas percepciones en cuanto a que la educación pública no satisface las aspiraciones de las clases sociales que prefieren y pueden pagar los servicios de escuelas particulares. Cuando hablamos del sector privado en la educación hacemos referencia al conjunto total de actividades escolares que, con o sin licencia gubernamental, son controladas por particulares y cuyos derechos de propiedad no están en disputa.

El sector privado se puede dividir en tres grupos, de acuerdo con los estratos sociales a los que presta el servicio: de élite, de sectores medios y de prestación de un servicio público. Asimismo, en su seno pueden distinguirse dos segmentos de acuerdo con su orientación: el laico y el 
religioso o confesional. Estos dos segmentos atraviesan a todos los tipos, niveles y modalidades de educación (Ornelas, 1995).

La mayoría de estas escuelas se declaran instituciones no lucrativas, laicas y mixtas. En general, su metodología de enseñanza-aprendizaje tiene fundamentos similares. Siguen los dos programas de estudio, el de español y el de inglés, utilizan libros de texto en español complementarios de los libros de texto gratuitos, y para el inglés emplean textos importados de Estados Unidos de América que son renovados periódicamente, entre tres y cinco años, de acuerdo con la evolución de los programas de ese país.

La educación privada es un conjunto heterogéneo de escuelas que, comparadas con el total nacional, nunca más de $10 \%$ del total, ha ejercido una influencia considerable en la formación de ciertos sectores sociales. Esto se hizo patente en la labor desempeñada por la escuela católica que sin duda logró, cuando menos hasta la década de 1970, mantener a través de sus colegios la cultura, la tradición y los valores de la Iglesia católica. Arraigada a un sistema impuesto por el Estado, su gran diferencia es la posibilidad de desempeñarse con bastante autonomía en sus principios, valores, métodos y funcionamiento, sobre todo en cuanto a la enseñanza de la religión, a pesar de la legislación adversa y las constantes restricciones impuestas.

Encontramos en la educación privada características particulares motivadas por diversos factores, sobre todo de índole económica e ideológica, que les adjudicaron ciertas ventajas si las comparamos con los planteles pertenecientes al sistema oficial. Los directivos de las escuelas privadas se distinguen, sobre todo las enfocadas a los sectores económicos privilegiados, por verse en la necesidad de desarrollar métodos educativos autónomos, en ocasiones comunes a un grupo de ellas, en otras, enteramente propios.

En pocas ocasiones se hace mención a la importancia que las instituciones educativas de educación privada tienen, y menos aún las consideraciones especiales que los directivos de las mismas, deben incluir en su perfil. Sin embargo, al revisar comentarios que el expresidente Felipe Calderón Hinojosa (2006-2012) realizó, en el 2008, en torno a la escuela particular, encontramos los siguientes ${ }^{11}$.

a) La escuela particular cristaliza dos derechos ya plasmados en papel y un tercero apenas en proceso de clarificación. El primer derecho - 
reconocido en la Declaración Universal de 1948, firmada también por México- es el de los padres a elegir la educación que les parece más adecuada para sus hijos. El segundo es el que brinda el arreglo institucional: el derecho a la libre iniciativa económica, de manera que la escuela pueda ser sostenida por un grupo que cobra cuotas, paga salarios, realiza compras y expide facturas. El tercero, que apenas está discutiéndose en los circuitos intelectuales del mundo, es el derecho a la libre iniciativa educativa: todos los seres humanos tienen derecho a proponer a otros, o a buscar de otros, los elementos que complementen su expresión, autoconcepto y conocimiento del mundo.

b) Necesitamos también una revolución educativa en las escuelas particulares. Los regímenes posrevolucionarios pensaron en la educación básica como un proyecto de pacificación y el mecanismo central para tener una identidad compartida, la idea fue extender la cobertura, no garantizar la calidad; homogeneizar la mentalidad, no propiciar la diferencia y el sentido crítico. El orgullo de la escuela particular era su promesa de alta calidad y de involucramiento intenso de los padres; la escuela particular se vio a sí misma como comunidad educativa, y no, como en la escuela oficial, un centro de trabajo.

c) Hoy que ya ha cedido la compulsión estatista (cedido, no desaparecido), la escuela particular tiene enormes déficit: hostigan para las inscripciones, pero brillan por su ausencia en las aclaraciones; aumentan sus cuotas, pero no la calidad del servicio; llenan sus folletos y juntas informativas con rimbombantes declaraciones sobre "el Proyecto Educativo", pero la práctica cotidiana es rutinaria, repetitiva, con una buena parte de los maestros malpagados, improvisados y/o resentidos; finalmente, y tal vez lo más grave, los alumnos se alejan artificialmente de la realidad social de México sin tener a cambio una educación mejor.

d) Lo que tiene de ventaja la escuela particular es una gestión más fluida (se contrata y despide directamente, el gasto se aplica de inmediato) y los padres son exigentes. La escuela particular tiene que demostrar los frutos de esas ventajas; la escuela pública tiene que adquirir esas ventajas, que no son propiedad exclusiva del mercado. Mejor gestión y participación no deben ser privilegio que sólo una minoría puede pagar. 
Por su parte, la escuela pública es resultado de un conjunto de impulsos y demandas sociales que se ha originado tanto en las élites políticas e intelectuales como en los movimientos sociales. Su carácter público, laico y gratuito es lo que ha permitido un consenso básico, en cuanto a un basamento cultural común, que permite mantener ciertos niveles de cohesión social; pero también la salvaguarda de estos principios es la defensa de valores tan importantes como la tolerancia y el respeto a la diversidad, e implica la conservación de un lugar de acceso a la educación para amplios sectores de la población.

La tensión actual sobre la escuela pública radica en que, con el adelgazamiento de las funciones del Estado sustentado en lógicas de racionalidad técnica e instrumental, el financiamiento se ha disminuido; cada vez más se responsabiliza a los padres de familia, a los directivos y a los maestros del sostenimiento escolar y de la eficacia y eficiencia de los resultados educativos.

La solución a largo plazo -y ése es el gran desafío de la transición del SEM- es hacer mejor, mucho mejor, a la escuela pública y elevar su potencial de ofrecer mejores oportunidades a cada vez mayor número de mexicanos. Sin embargo, ése es un reto de gran envergadura, ya que la expansión escolar, con todo y que brindó oportunidades reales de movilidad social a vastos sectores, no tuvo la fuerza e intensidad suficientes como para influir en una mayor igualdad social (Ornelas, 1995: 228).

De esta manera el atraso escolar afecta a los fragmentos sociales tradicionalmente desprotegidos y es de esperarse que la actual Reforma Educativa promulgada por el gobierno del presidente Peña Nieto, demuestre en hechos, la implementación de la misma y no sólo su divulgación escrita.

De tal forma, encontramos que el liderazgo de las instituciones educativas, tanto públicas como privadas, enfrenta grandes retos comunes en materia de calidad en la formación inicial de los docentes y calidad en los planes y programa de estudios; sin embargo, por su misma esencia se requieren competencias profesionales diferentes en cuanto a la gestión administrativa y de los recursos humanos, así competencias relacionadas con el involucramiento de la comunidad educativa. Pero ante todo, deben priorizar ambos sectores, la implementación de la Reforma Educativa 2013 
como parte de su planeación estratégica a corto y mediano plazo, de lo contrario, difícilmente se verán avances en la calidad educativa y el directivo escolar, mucho puede hacer en torno a este tema.

\section{Docentes del SEM}

Los maestros de educación preescolar, primaria y secundaria, de educación física y educación especial, realizan sus estudios en escuelas normales, públicas o privadas. Esta preparación es considerada de nivel superior razón y los egresados reciben el título de licenciado. En México existen 473 escuelas normales, de las cuales $69 \%$ son públicas. Por su parte, la Universidad Pedagógica Nacional (UPN), organismo desconcentrado de la SEP, forma maestros de educación básica en diversas especialidades de nivel licenciatura y equipara a maestros que no tienen licenciatura; tiene una sede y seis unidades en la ciudad de México. En los estados de la República existen en 68 sedes que antes de la federalización educativa, en marzo de 1992, formaban parte de esta Universidad y ahora son controladas por los gobiernos estatales. Los 47 Centros de Actualización del Magisterio (CAM) también forman parte del subsistema de formación y actualización.

El acceso a la profesión docente está regulado por instrumentos de naturaleza administrativa y laboral que acatan las disposiciones de la Ley Federal de los Trabajadores al Servicio del Estado. Los profesores de educación básica son empleados del Estado y, por lo tanto, están bajo normas semejantes para todos los empleados del servicio público.

El acceso al servicio educativo depende de las necesidades de la SEP y la contratación es facultad exclusiva de dicha dependencia. El Reglamento de las Condiciones Generales de Trabajo del Personal de la Secretaría de Educación Pública señala que existen dos tipos de trabajadores: de base y de confianza. Se considera personal de base a quienes tienen nombramiento definitivo y más de seis meses a partir de la fecha de su ingreso en una plaza que no sea de confianza. Los nombramientos que expide la SEP son definitivos, interinos, por tiempo fijo o por obra determinada. Los nombramientos para cubrir vacantes temporales que no excedan de los seis meses los hace libremente la Secretaría.

Las plazas de la SEP pueden ser de reciente creación o por vacantes definitivas. De acuerdo con las necesidades, se pueden crear plazas iniciales o suplir vacantes con carácter temporal y proceder a la contratación de 
personal. Los egresados de las normales tienen asegurado un puesto de trabajo, razón por la cual muchos estudiantes optan por seguir esta carrera. En el Distrito Federal, la SEP tiene un convenio con la Escuela Nacional de Maestros para asignar a los egresados una plaza en forma automática. En algunos estados existen convenios semejantes y en los que no los hay esa relación opera en forma práctica. Los requisitos para ingresar al cuerpo docente dependen de la plaza y de la categoría.

En general, uno de los requisitos es haber obtenido el título de maestro normalista o de conocimientos equivalentes comprobados. En ciertos casos, como en algunos servicios que se proporcionan a través del Consejo Nacional de Fomento Educativo (CONAFE) y del Instituto Nacional de Educación para Adultos (INEA), el personal docente tiene nivel de secundaria o de bachillerato acreditado. En el sector privado los requisitos académicos para la contratación son semejantes a los establecidos por la SEP: tener estudios de normal nivel a licenciatura o equivalentes (Álvarez Mendiola, OEI, 1994).

En términos de las instituciones públicas, son los docentes con plazas, temporales o definitivas, quienes pueden accedes a puestos de dirección y supervisión escolar; por ello la importancia de entender el contexto del docente, tanto en su formación inicial, como en su formación continua.

\section{Conclusiones}

Durante varias décadas, el liderazgo educativo en México ha sido un tema de poco análisis, de poca importancia desde una perspectiva pedagógica, pero de alto impacto para los intereses políticos de las comunidades.

En México, la tan anhelada Reforma Educativa ha sido un tema complejo de manejar; sin embargo, por distintos factores, entre ellos la presión/oposición del Sindicato de Trabajadores de la Educación (SNTE) y, hoy día muy fuerte por parte de la Coordinadora de Trabajadores de la Educación (CNTE) han frenado la promulgación e implementación de los cambios que tanto requiere el país en materia educativa. Aunque las bases se trabajaron desde el sexenio anterior, del ex Presidente Felipe Calderón Hinojosa, no fue sino hasta el actual gobierno, y pasados unos meses de negociaciones y adecuaciones, cuando finalmente el Presidente Enrique Peña Nieto, promulgó la Reforma Educativa del Sistema Educativo Mexicano en febrero 2013, que curiosamente fue temporalmente paralela a 
la detención de la líder Magisterial Elba Esther Gordillo, quien desde hace varias décadas encabezó el coto de poder del SNTE y se le han atribuido fuertes sumas de dinero desviado a otras acciones que poco o nada tienen que ver con la educación. Así como en los últimos meses el SNTE se ha alineado paulatinamente en varios de los intereses educativos del Estado, la CNTE ha fortalecido su oposición, tornándose en un elemento de freno y presión social, no sólo en el ámbito educativo, sino también en el político; mediante amenazas a nivel nacional, que han ocasionado fuertes desajustes de la implementación en tiempo y forma, de la Reforma Educativa.

Es un hecho que en México no existía una selección y formación directiva formal dentro del Sistema Educativo, pero se está intentando iniciar; por ello, podemos plantear grandes oportunidades para impulsar esta figura, que tiene una importancia estratégica: "[...] las maneras de escoger a ese profesional deben ser pensadas con sumo cuidado. Éste es un campo abierto para experiencias innovadoras, combinando los criterios de competencia profesional con legitimidad de liderazgo y aceptación de autoridad" (Namo de Mello, 2003: 66). El director escolar se podrá legitimar por medio de los resultados que vaya demostrando.

Si consideramos el panorama que detallamos a lo largo de este artículo, resulta un gran paso el que ha dado la Reforma Educativa 2013 en cuanto al tema de Liderazgo Educativo, por incluir la selección, desarrollo y delimitación de funciones de los roles de gestión como supervisores, directivos y coordinadores; sin embargo, está lejos, aún en el mismo documento, de que México de la importancia que tienen el director de la institución educativa -tanto en el ámbito público, como en el privado- como estratega e impulsor del cambio en la escuela, por medio de involucramiento de la comunidad educativa en su conjunto, para que, con base en los planes estratégicos, se mejore la calidad educativa.

\section{Notas}

1 Organización de Estados Iberoamericanos. http://www.oei.es/quipu/mexico/index.html. Fecha de consulta: 18 de mayo de 2015.

${ }^{2}$ Sobre el concepto dignidad, nosotros entendemos que "el valor y la dignidad profunda de la persona humana consiste, $[. .$.$] , en ser persona, sujeto de una naturaleza que le hace capaz de$ conocer y amar" (Cardona, 2001: 139-140). 


\section{I. Parés - Liderazgo Educativo en México}

3 Álvarez Mendiola, OEI, 1994. http://www.angelfire.com/ms/camm/sem.html. Fecha de consulta: 8 de mayo de 2015 .

4 Descentralización significa transferir parte de las funciones y recursos del sistema educativo federal, incluyendo trabajadores docentes y no docentes, así como planta física instalada, a los gobiernos estatales (Prawda, 1987).

5 Álvarez Mendiola, OEI. (1994). En www.angelfire.com/ms/camm/sem.html. Fechas de consulta 25 de abril de 2015.

6 Consultar: http://www.sep.gob.mx/wb2/sep1/sep1_BOL2971107 en su sección de noticias que se actualiza periódicamente. Fecha de Consulta: 13 de noviembre de 2007.

7 En México el concepto de escuela privada es equiparable al de escuela particular y lo usaremos de manera indistinta.

8 Palabras de Edgar Morin: "[...] el siglo XX fue el de la alianza de dos barbaries: la primera viene desde el fondo de la noche de lo tiempos [...]. La segunda, helada, anónima, viene del interior de una racionalización que no conoce más que el cálculo e ignora a los individuos, sus cuerpos, sus sentimientos, sus almas y multiplica las potencias de muerte y de esclavización técnico-industriales" (Morin, 1999: 66). Esta reflexión ayuda a entender el contexto de la escolarización del siglo XX, pues si no se conoce la herencia, es difícil entenderla y proyectarla hacia el siglo XXI.

9 Calderón, 2008. http://impreso.elfinanciero.com.mx/pages/ejemplar.aspx. Fecha de consulta: 6 de febrero de 2008.

10 Confrontar con http://www.latarea.com.mx/articu/articu16/garcia16.htm. Fecha de consulta: 8 de febrero de 2008 .

11 TORRES V. http://biblioweb.dgsca.unam.mx/diccionario/htm-/articulos/sec_20.htm. Fecha de consulta: 5 de febrero de 2008.

\section{Referencias de Consulta Bibliohemerográficas}

Andere, E. (2003). La educación en México: un fracaso monumental. ¿Está México en riesgo? México: Planeta.

Cardona, C. (2001). Ética del quehacer educativo. Madrid: RIALP.

Cardona, P. (2005). Cómo desarrollar las competencias de liderazgo. Barcelona: IESE.

Carreño, M., Colmenar, C., Egido, I. y Sanz, F. (2002). Teorías e instituciones contemporáneas de educación. Madrid: Síntesis Educación. 
Instituto Nacional para la Evaluación de la Educación (2007). Panorama educativo de México 2007. México: INEE.

López Delgado, M. (2015). The Appointment of School Leaders in Mexican Primary Schools: an Exploratory Study of the System of Promotion. International Journal of Educational Leadership and Management. Vo.l. 3. No. 1. Enero 2015: Hipatia Press.

Meirieu, P. (2004). En la escuela hoy. Barcelona: Octaedro.

Morin, E. (1999). Los siete saberes necesarios para la educación del futuro. México: UNESCO.

Namo de Mello, G. (2003). Nuevas propuestas para la gestión educativa. México: SEP-UNESCO.

Ornelas, C. (1995). El Sistema Educativo Mexicano: la transición de fin de siglo. México: CIDE, FCE, NF.

Prawda, J. (1987). Logros, inequidades y retos del futuro del Sistema Educativo Mexicano. México: Grijalbo.

Prawda, J y Flores, G. (2001). México educativo revisitado: reflexiones al comienzo de un nuevo siglo, con una cierta mirada. México: Océano.

Secretaria de Educación Pública (2015). Perfiles, parámetros e indicadores para personal con funciones de dirección, supervisión y de asesoría técnica pedagógica. Subsecretaría de Educación Básica. Coordinación Nacional del Servicio Profesional Docente. México: SEP.

\section{Referencias de Consulta Electrónicas}

Álvarez Mendiola G. (1994). Sistema Educativo Nacional de México. Secretaría de Educación Pública y Organización de los Estados Iberoamericanos. www.angelfire.com/ms/camm/sem.html. Fecha de consulta: 8 de febrero de 2008.

Calderón, D. Escuelas privadas, necesidades públicas. El Financiero, sección Opinión. http://impreso.elfinanciero.com.mx/pages/ejemplar.aspx. Fecha de consulta: 6 de febrero de 2008.

Organización De Estados Iberoaméricanos. http://www.oei.es/quipu/mexico/index.html. Fecha de consulta: 18 de mayo 2015.

Torres, V. (s/f). Educación privada en México. http://biblioweb.dgsca.unam.$\mathrm{mx} /$ diccionario/htm/articulos/sec 20.htm. Fecha de consulta: 5 de febrero de 2008 . 
172 I. Parés - Liderazgo Educativo en México

Secretaría de Educación Pública. Programa Sectorial de educación 2013-2018. http://www.sep.gob.mx/es/sep1/programa sectorial de educacion 13 18\#.VYsivuvW5cg. Fecha de consulta: 29 de mayo 2015.

Isabel Parés is Professor and Researcher at the School of Education from Universidad Panamericana, México.

Contact Address: ipares@up.edu.mx 